\title{
How People and Stakeholders Shape Standards - The Case of IEEE 802.11
}

\author{
Kai Jakobs \\ RWTH Aachen University, Informatik 4, Ahornstr. 55, 52074 Aachen, Germany \\ kai.jakobs@cs.rwth-aachen.de
}

\begin{abstract}
Following the 'social shaping of technology' approach, this paper provides a brief discussion of the relations that exist between different stakeholders in ICT standardisation. It then discusses the impact exerted by the individuals who populate a standards body's working group, and how this body's voting rules impact its final standards. The paper primarily draws upon a qualitative empirical study. In particular, it will use the IEEE 802.11 committee as a real-world sample group to further highlight the issues discussed more theoretically above.
\end{abstract}

Keywords. Standards, Standardisation, Social Shaping of Technology.

\section{Introduction and Motivation}

Colloquially, the term 'standard' is used for specifications of very diverse origins. Windows and SAP/R3 are (industry/proprietary) standards, XML and UML are (consortium) standards, and UMTS and ISDN are (formal) standards. Yet, regardless of their respective origin, (successful) standards are crucial building blocks of all virtually all ICT systems. Think of it - the success of the Internet, for instance, may to no small amount be put down to the sheer existence, simplicity and effectiveness of its core protocols, TCP/IP.

Thus, standards now under development will be an integral part of future ICT systems, and will to no small extent define their functionality. In a way, this provides us with an opportunity for taking a glimpse into the future, albeit possibly a blurred one. What's more, there may even be a chance to pro-actively try and shape these future systems by shaping today's standards setting. After all, a standard does not come out of the blue, but is a product of standards development process and of the environment within which it emerges. Thus, if the characteristics of this environment were known this might enable an early shaping of tomorrow's ICT systems.

Perhaps a bit surprisingly, I would consider 'people' to be one of the major influencing factors in standardisation. After all, a standard originates from a technical committee or working group, where a group of individuals try to find a working solution to a given problem; it is here were the basic technical decisions are made. That is, we will need to look at the motivations, attitudes and views that influence 


\section{Kai Jakobs}

these people's work if we want a better understanding of why a particular specification emerged the way it did.

The remainder of the paper is organised as follows. Some brief theoretical background on the Social Shaping of Technology (SST) is provided in chapter 2. Subsequently, chapter 4 highlights the impact an individual may have on the outcome of a standards working group, and discusses the impact of the working group's voting rights. Finally, some brief conclusions are presented in chapter 5.

\section{Some Brief Theoretical Background}

Technological artefacts in general, and especially such powerful representatives as ICT systems, will exert potentially strong impact on their environment. Yet, the same holds for the reverse direction. That is, complex interactions between ICT systems and their respective environments can be observed. Technology may assume both an active and a passive role; that is, technological artefacts and their environment are mutually interdependent. The environment within which technology is used and employed has, among others, social, cultural, societal, and organisational behaviours, rules and norms. It is clear that technology cannot emerge completely independent from such external influences. However, the impact ICT may have on organisations, or indeed society as a whole, has thus far attracted considerably more attention than the powers that shape this technology in the first place. Especially the impact of ICT within organisational settings (e.g. on a company's performance, or its role as an enabler of business process re-engineering) has been subject to a vast number of studies and analyses. Keywords such as 'organisational transformation' 'technology management', and 'management of change', can frequently be found in the literature, typically denoting studies on how the introduction and subsequent use of ICT have changed a particular organisational environment - for better or worse. Only recently has the reverse direction of impact been studied, i.e. the one exerted from organisational and societal conditions on technology.

\subsection{Social Shaping of Technology}

Two mutually exclusive schools have dominated research on technology and organisations until the early eighties (and are still in evidence). Proponents of the 'organisational choice' model consider technology as a vehicle to both reflect and foster the interests of particular groups; the process of change can be, and indeed is, shaped entirely by policy makers or organisation's managers; these actors have unlimited technological choices. "Technology has no impact on people or performance in an organisation independent of the purposes of those who would use it, and the responses of those who have to work with it" [1]. In contrast, 'technological determinism' in essence postulates that ICT determines the behaviour of organisations, that the consequences of manipulating a given technology will always be the same, independent of who manipulates and within which context. It follows that, according to this view, organisations have little choice but to adapt to the 
requirements of technology; particular paths of technological development are inevitable; like organisations, society at large also has no other choice but to adapt [2].

Research into SST largely emerged as a response to technological determinism (see e.g. [3] for an in-depth introduction). SST acknowledges that technology indeed has an impact on its environment, but that at the same time it is well framed through technical, but rather more through e.g. organisational, societal, cultural and economic factors. In particular, SST attempts to unveil the interactions between these technical and social factors. Abandoning the idea of inevitable technological developments implies that choices can be made regarding, for instance, acquisition, the use, and particularly the design of technological artefacts. There may be a broad variety of reasons upon which these choices are based. In an organisational context this may include purely technical reasons, as e.g. the need to integrate legacy systems, but decisions may also take into account company particulars, as for instance organisational or reporting structures. These choices, in turn, may lead to different impacts on the respective social or organisational environments. Thus, studying what shaped the particular technology offers a chance to proactively manipulate that very impact expected to result from this particular choice. At the same time this capability should also contribute to the prediction - and thus prevention - of undesirable side effects potentially resulting from a new technology. After all, technology tends to have other effects besides those actually intended, and these effects need to be explored as well. On the other hand, the respective environment shapes technical artefacts and systems during design and in use, i.e. at the site of the actual implementation.

\subsection{Shaping Standardisation}

Technological artefacts embody, and thus transfer, their respective environment of origin. The same holds for standards, which result from work in a committee. This alone implies that adaptations will subsequently be required if a system is to be exported to other markets, or user organisations, with different environments. "The shaping process begins with the earliest stages of research and development" [4]. This observation points to a direct link between the shaping of technology and standardisation activities. Especially since the advent of pro-active standardisation technological systems have increasingly been rooted in standards activities. In fact, the shaping of technology needs to start here.

Standards emerge through the co-operation and joint efforts of different individuals in technical committees and working groups. Whilst in theory these individuals act in their capacity as 'independent' experts, their views, beliefs, and prejudices have to a considerable degree been shaped by the environment within which they live and, especially, work. That is, various factors that may shape technology are also likely be channelled into the working groups of the international standards setting bodies. The corporate environment of the group members' respective employer, for instance, will have a major impact on the different visions of how a technology should be used, and the ideas of how this can be achieved. Therefore, they will also exert a significant impact on the work of the committees. This holds especially in the case of 
anticipatory, or pro-active, standards which specify new services from scratch, and thus offer the opportunity to incorporate to some (a considerable?) degree the particular presumptions, views, and ideas of the members of the originating committee (and their respective employers).

A reactive standard (i.e. one that basically just rubber-stamps an existing technology) will likewise transpose the environment from which it emerged; this will be the corporate environment (using this term very loosely) of its inventor (i.e. typically a manufacturer or a service provider) who originally specified the system upon which the standard will be based. Thus, this company's visions will implicitly be embodied in the standard specification, together with the ideas and views of its representative(s).

A first attempt to put together the individual factors that contribute to the shaping of a standard yields the following list:

1. External forces, including e.g.

- advances in science and technology,

- prevailing societal norms,

- legislation.

2. The context within which a WG works, including e.g.

- the rules and by-laws of the respective Standards Setting Body (SSB),

- the SSB's 'culture'.

3. Individual major stakeholders' (vendors and possibly large users) preferences, including e.g.

- technical interests

- corporate strategies.

4. The immediate context from which a standard emerges, including e.g.

- WG members' views, ideas, competencies, attitudes, backgrounds, etc,

- members' communication capabilities,

- the roles they assume.

In the following, I will look more closely first at 3 and then at 4.

\section{Relations Between Stakeholders}

The procedures adopted by the individual SSBs may differ with respect to various criteria. In particular, the criteria upon which voting power is assigned to members differ. The options range from 'one countrylcompanylindividual - one vote' (applied by e.g., ISO/W3C/IEEE) to rather elaborate schemes with different membership levels that basically allow companies to 'buy' voting power. Here, the 'price' (i.e., the membership fee) typically also depends on the size or revenue of the company (ETSI, for instance, uses such a scheme).

At least the former, rather egalitarian approach suggests that the degree of control over, and influence on, the standards setting process is about equally distributed between the different types of stakeholders. This, in turn, yields the model of the standardisation process as depicted in Figure 51 It shows the 'ideal' situation, with all stakeholders having a (more or less equal) say in the standards setting process. 


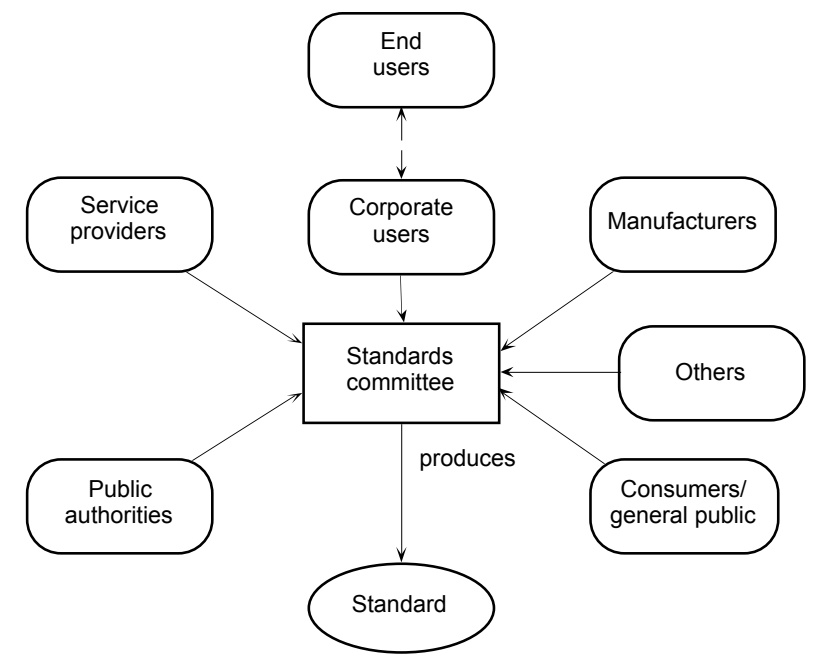

Fig. 1. A naive model of the standards setting process (adapted from [5])

This - fairly technocratic - model still underlies many SSBs' rules and processes. Unfortunately, it ignores organisational and social aspects, and does not assume any links or interrelations between the different stakeholders.

As a consequence, this ideal scenario is far removed from reality - at least according to some earlier research (see e.g. [6]). In fact, it appears that so far IT standards development has almost exclusively been technology driven; with standards produced solely reflecting providers' and implementers' priorities like, for example, manageability rather than usability. This can largely be attributed to the fact that relevant standardisation committees have typically been dominated by vendors and service providers (see also [7] for a more elaborate discussion). Accordingly, a more realistic model is called for.

Obviously, there are also relations between these various stakeholders outside the standards setting process, the most obvious one being customer - supplier. Those relations may well have considerable impact on both sides' activities and conduct in standardisation. For instance, most users (except for some very large and sophisticated ones) would rather try and resolve problems locally (by e.g., enhancing a standards implementation to meet local needs). They rarely get involved in setting standards that may eventually meet their requirements.

Those entities that form the 'third estate' in standards setting are a different case altogether. Although they represent the vast majority of stakeholders these groups have extremely little say in the standards setting process. This holds despite the fact that organisations such as $\mathrm{ANEC}^{1}$ for the consumers and NORMAPME ${ }^{2}$ for SMEs are actively participating in selected standard working groups on behalf of their respective constituencies.

\footnotetext{
${ }^{1}$ The 'European Association for the Co-ordination of Consumer Representation in Standardisation'.

${ }^{2}$ The 'European Office of Crafts, Trades and SMEs for Standardisation'.
} 
Figure 2 depicts the actual situation more realistically. Specifically, it highlights two phenomena. First, manufacturers and service providers seem to act as a sort of buffer or filter between corporate users and standards committees [6] - whether deliberately or not - in that they filter their customers' requirements. Also, in cooperation with the users they provide individual solutions to meet their respective customers' needs. This way, they potentially compromise to some extent the idea of many ICT standards, i.e., to provide interoperability. This also contributes to reducing the number of users in standards setting.

Second, some sort of invisible 'shield' keeps potential input from standardisation's 'Third Estate' away from the working groups. This 'shield' is largely rooted in a lack of financial resources (actively contributing to standards setting is a costly business, see e.g., [8]) and of qualified personnel. This is frequently combined with inadequate knowledge about the value of standards in general, and of the potential value of active contributions to standards setting in particular.

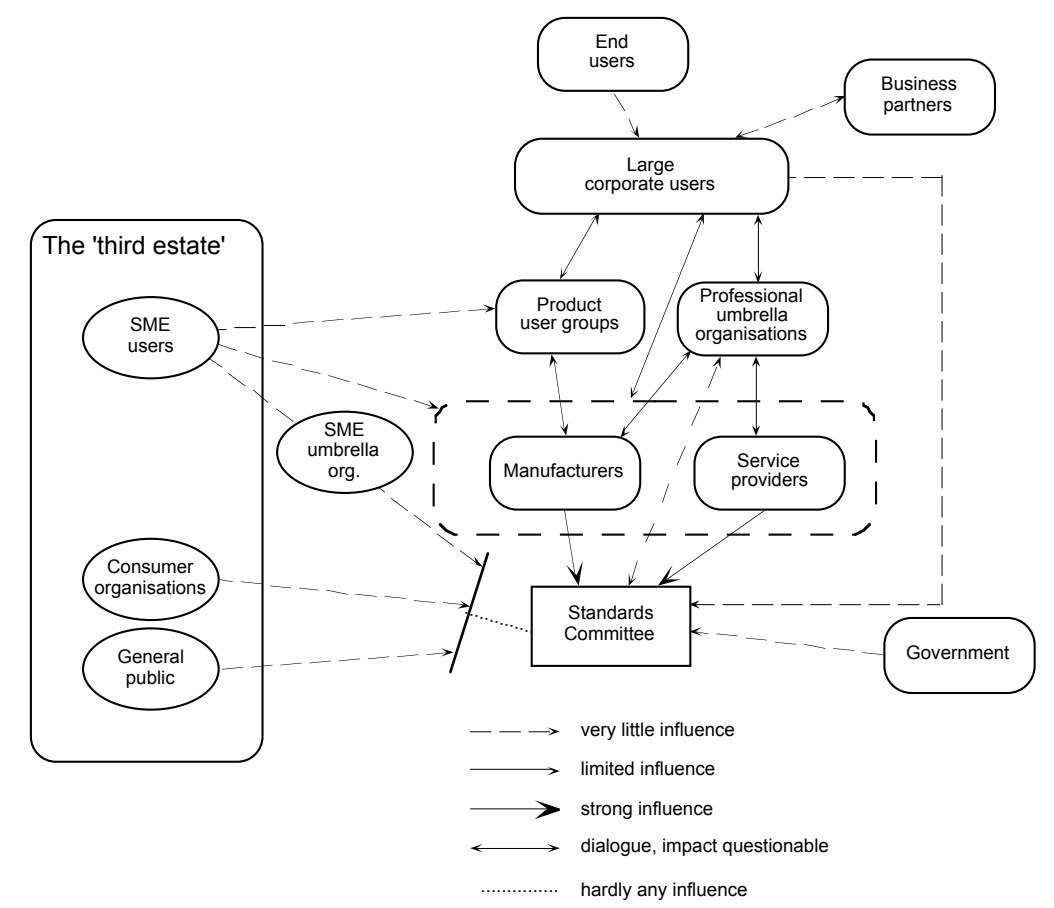

Fig. 2. A more realistic view of the relations between stakeholders in standardisation \{taken from [6]) 


\section{The Individual's Role}

\subsection{A Little Background}

The above already suggests that different players exert varying degrees of influence over an SSB's process, depending on their respective levels of interest in a new standard, but also on rather more mundane aspects like deep pockets and market power. However, at the end of the day, a standard's specification results from the efforts of the members of an SSB's working group. Consequently, these individuals' motivations, attitudes and views are very likely to have an influence on their contributions to the standards setting process, and thus on its outcome.

Various factors, which do not necessarily bear a relation to the technology to be standardised, are channelled into an SSB's working groups (WGs), and shape the process outcome. [9] argue that the respective corporate environments of the WG members' employers, for instance, are playing a major role here. The different visions of how a technology should be used, and the ideas of how this can be achieved are shaped by these local environments, which therefore also exert an impact on the standardisation work. This holds especially in the case of anticipatory standards, which specify new services from scratch, and thus offer the opportunity to incorporate to some degree the particular presumptions of the (more outspoken) members of the originating WG. Yet, a reactive standard will likewise transpose the environment from which it originally emerged; i.e. the corporate environment of its inventor who specified the system upon which the standard will be based.

\subsection{Perceived Influential Factors}

To find out which such non-technical factors actually do play a role, and thus to better understand why a standard emerges the way it does, we need to have a closer look inside WGs.

In a (smallish) study of factors that influence the standards setting process at WG level within ISO and ITU-T, [7] showed that a WG's decisions are taken for a variety of reasons, a proposal's technical merits being but one of them. For example, about one out of three respondents from ISO observed that it is individuals that are most powerful.

"Oddly enough, it's been my experience that_individuals_dominate ISO.

Sometimes the individual will have a powerful multinational corporation or government/national interest on their side, but the bully pulpit is controlled by individuals, and only those with a strong sense of purpose survive."

Much in line with the above observation, many respondents from ISO and ITU stress that speaking out at meetings for or against a proposal is the most important single factor influencing technical decisions. That is, even good proposals will hardly be considered if nobody is available to explain or defend them at meetings.

"For any given technical decision the presence of supporters/opponents weighs heavily, for in practice unless there is someone or some organization 
that champions a solution and pushes it forward it does not get as much consideration/exposure as alternate solutions. That is, group members typically do not delve into researching solutions that someone happened to send us unless such solution at first glance seems to be overwhelmingly good. More likely the members push the solutions that they already understand."

Along similar lines, the influence of those who are prepared to put in extra work should not be under-estimated. These two aspects are probably linked - those with strong views are more likely to be inclined to invest time and effort to get their views through.

"Often the group "leaders" (including formal editors, and strong personalities who are not formal leaders) have tremendous influence. (This is not necessarily bad.)"

Another factor identified as influential - though overall said to be of lower importance - is a proposal's technical merit; underlying company interests may also have to be taken into account.

"Unless you are at the meeting, your view is not taken into account (no matter how technically correct it may be). This is the overwhelming factor that decides the content of the standard. Company interests (political influence at the voting level) is the next priority. Technical merit is of little importance standards are usually a poor compromise of many strong views".

"The technical viability of a decision does carry great weight. As almost all members at the technical committee meeting level are engineers, the technical prowess of the solution, tied with the credibility (knowledge) of the person presenting it are very influential. On occasion, a company which already has a product back in their labs will also prove to be a formidible opponent."

The above observations stress the importance of the rather more non-technical aspects of the standardisation process. Clearly, these aspects are strongly linked to the individual WG members' attitudes and approaches. However, as stated above, these, in turn, are to a considerable degree shaped by their respective work environments.

\subsection{The Case of IEEE 802.11}

In the IEEE, membership - including voting rights - in the 'international programme' is assigned to individuals (as opposed to e.g., companies). That is, here as well a closer look at the roles, views, and motivations of WG members is of interest - do WG members actually act based on their personal views and perceptions, or do other factors play a role, too? To this end, a questionnaire comprising 16 open ended questions was distributed to a number of individuals who played an important role during the development of the IEEE 802.11 set of standards [10]. The findings from this survey should be taken as a snapshot - the idea was to shed some light on different aspects associated with the IEEE's 'individual membership' approach.

Almost all respondents have a strictly technical background, with job titles such as 'communication engineer' or 'system architect'. They were all very active in the process, and typically attended almost all meetings (which gave them almost permanent voting rights; they are conferred after attendance of 3 out of 4 consecutive plenary meetings, and need to be maintained through continuing participation in both 
meetings and ballots). However, only very few had previous experience in standards development. Obviously, the initial motivations for attendance differed, but interest in the technology dominated (which is no big surprise considering the respondents' engineering background).

With primarily engineers populating the WGs one could be inclined to suspect that influence during deliberations is based on the respective technical merits of the proposals on the table. Yet, it appears that other factors are at least as influential here. Two typical responses:

"Most influence came from 1/3 powerful organizations (companies), 1/3 strong technical proposals, 1/3 active and respected company representatives".

"The influence came through a combination of strong technical proposals, active representatives and powerfull organizations".

Standards setting is a costly business (see e.g., [8]; things have not improved since then). Thus, a link between the economic strength of a company and its interest in a specific standard on the one hand, and the level of its representation in the body developing this standard on the other may safely be assumed. Indeed,

"There are active/respected representatives from most large organizations because it costs so much to commit people to creating the standard, and active/respected representatives gravitate to organizations that support the standards effort",

Said "large organizations" were typically (chip) manufacturers:

"90\% of all attendance was by manufacturers. Manufacturers are (and continue to be) the most influential in the committees as they are primary companies responsible for creating and distributing the technology".

To a considerable extent, developing standards is about the distribution, and the use, of power. The above suggests that in the case of the 802.11 power was - for obvious reasons - primarily with large manufacturers. With their vested interest in the technology they were prepared to invest heavily in R\&D efforts, and to send representatives who were widely respected in the industry to the WG meetings. These individuals came armed with good proposals (the results of the R\&D efforts), for which they could make a strong case. Strong corporate interest, good proposals and respected and knowledgeable proponents seems to be a wining combination (whether or not two out of these would do remains an open issue). In the words of a respondent, influence in the WG

“ ... is a combination [of e.g., powerful organisation, deep pockets, strong technical proposals, active/respected representatives], but the companies that were the strongest in the market also put most effort in the standard by means of number of people, proposals, technical knowledge, experience in the field. But there are also examples of small companies with very smart/ respected representatives who took and got a lot of bandwidth".

These quotes seem to suggest that corporate interests were at least very visible inside 802.11. Yet, the question remains if WG members actually represented their respective employers' or clients' proposals, or if they supported other proposals they felt them to have more merits (for instance, because they considered them technically superior). If the former were the case, all representatives of a company that submitted a proposal should rally behind it. In fact, respondents agree - albeit not unanimously 
- that such behaviour could normally be observed. Of course, representatives of a company defending their employer's proposal is not necessarily a contradiction to 'individual membership'. After all, the developers of a corporate proposal were most likely the ones also attending standards meetings; this way, their interests and those of the employer happened to be aligned. As one respondent put it:

"[Different representatives of one company] mostly acted in unison based on their affiliaton, and usually because they had a vested interest in their proposal or position succeeding ...."

In addition to such vested interests, fear of reprimand and reprisal might also be behind a vote:

"In general, when a company's rep did not represent the affiliations point of view, they tended not to appear at the next meeting. There are expections to this rule, but in general, if you work for a company, you are voting for their proposal".

While most respondents agree that supporting their employer's or client's proposal was the norm, they also agreed that deviations from this behaviour could be observed as well. However (and this suggests that fear of retaliation did not just come out of the blue),

"This was not a frequent phenomenon as far as I can tell. But there are examples of individuals who did (for whatever reason, sometimes they even self did not notice that they pleaded against their own company). I can think of one succes, but the individual lost (left?) his job afterwards".

Apparently, potential reasons for rogue acting (and voting) were diverse, the ambition to standardise on the best technical solution being a comparably popular one:

"... there were a number of very good people who worked toward the creation of the best standard that could be formed regardless of their companies position and agenda".

However, acting 'politically' is also not unheard of:

“... people would purposely vote opposite to their affiliation to *appear* fair minded".

Similar behaviour can be explained by exploiting IEEE rules:

"Other times they would vote contrarily when it could be predicted, or sometimes just in case, the vote would confirm that alternate position anyway. That would ensure that the company had at least one vote on the prevailing side so that indidvual could later make a motion for reconsideration - again that's another political ploy".

The latter two reasons for 'acting individually' are really cases of 'corporate tactics'. Thus, so far, it would seem that only some cases of 'individualism' can be explained by WG members' acting as individuals (as opposed to 'company reps').

The idea of 'individual membership' also implies that voting behaviour should not change with of WG-member's new affiliation, or with a consultant's new client. No clear picture emerged here. Still, a concrete observation by one respondent:

"Yes. A change of affiliation either as an employee or consultant has caused changes in on formerly held positions. A recent case in the IEEE 802 where two companies had brought in opposing technologies resulted in a stalemate position. The larger corporation purchased the smaller opposing technology 
company. So there became a committee where all the members were the same as before but the purchased company voters now had a new affiliation and voted accordingly".

Even if only some respondents reported such occurrences it seems safe to assume that at least several WG-members do change views depending on those of their current employer (which is perfectly understandable).

With a group of engineers discussing technical matters one should not be surprised to find evidence of the 'Not Invented Here' syndrome; likewise clashes of egos may be suspected. Respondents do indeed report such incidences that obviously occurred quite frequently. One responded observed that

"Many members can not separate valid technical criticism from "your baby is ugly". This is more frequent than necessary".

Such clashes may be over both personal and corporate views (e.g., if a company depends on a certain technology to be standardised), or over procedures. This is little surprise, as 'being outspoken' and 'having a sense of purpose' are essential attributes for successful standards setters [7]. At the same time, respondents noted that such personal clashes might well go hand in hand with clashes of corporate interests,

“... and it was more of a combination of both ego and money. Many clashes were driven due to big investments in company technology directions where the direction of the standard was important to the financial health of the companies involved".

Finally, the observation that existing implementations might well have a detrimental effect on a proposal's chances of being accepted is interesting.

"Technical merits are important but never the most important. Implementability, time to market (for all), fairness are equally important to drive decisions".

Obviously, the desire not to favour one company (the implementer) over others plays a role, too. This - rather striking - aspect surfaced quite frequently,

"Solutions already implemented did play a strong role, but could also be a strong reason to change things, to level the playing field (by forcing changes for certain vendors that already had an implementation)".

"I have never seen that a decision is taken that is in the benefit of only one company (because it already has solutions/products)".

And, even more strongly:

"No four organizations can make 802.11 do anything."

Even if the latter may be a slight exaggeration, these comments suggest that (many) members of the 802.11 groups were not prepared to let their work be overly dominated by corporate interests, and also that at least some of them were actively acting against any such dominance.

Accordingly, finding as many allies as possible, and forming strong alliances is an integral part of the game ('if you scratch my back, I'll scratch yours'). This necessity is not least triggered by the IEEE balloting process, which requires a $75 \%$ level of support for a proposal to enter the next stage of the process.

"With respect to $802.11 \mathrm{DS} P H Y$, main issues were agreed to by a coalition of companies out side of IEEE meetings and then were brought into IEEE 802.11 for debate. THis coordination between NCR/Aironet/Harris ensured sucess of $802.11 b^{\prime \prime}$. 
"In the end (the important decisions) are influenced most by the strength of companies (number of voters) and coalitions between companies. I have never seen that a decision is taken that is in the benefit of only one company ( because it already has solutions/products)".

These observations suggest that once everything has been said and done the decision about success and failure burns down to a simple head-count. A number of individual voters together form a 'corporate vote' (there may be exceptions), and enough such 'corporate votes' (i.e., a strong coalition) lead to the success of a proposal.

\section{Brief Summary and Analysis}

The survey responses draw a somewhat ambivalent picture. On the one hand, it seems that the majority of members of the 802.11 WGs have a very strong sense of fairness - they try not to allow a single powerful company, or a group of them, to dominate the process, may well consider existing pilot implementations as an unfair advantage and accordingly reject the associated proposal. On the other hand, it is safe to say that the majority of the leading figures are coming from exactly these powerful companies - they have the means and the motivation to invest heavily in the standards setting process, as the return on investment may be enormous. In addition, their employees are likely to be motivated to assume formal roles in the process (Chair, secretary, technical editor, etc), thus getting additional influence.

Overall, it seems that WG members cast their votes at least with a view towards their respective employers' business interests. Yet, exceptions from this seem to notso-infrequent, and typically aim at technically superior solutions. Likewise, the reports about WG members adapting their point of view to the one held by their current employer do not hint at strong personal opinions (rather at pragmatism). Thus, here again we do not see a homogeneous picture (of course, it is hard to vote against your employer's interests when you see people being fired for having done exactly that; another course of events not entirely unheard of, according to some respondents). Then again, the apparently fairly frequent clashes of egos suggest strong feelings about a proposal (there may be other reasons involved as well, though).

All in all, I do not believe that 'individual' membership is making a big difference. The responses from 802.11 members are pretty much in line with those from members of other standards bodies (ISO also prescribes that committee members "act in a personal capacity" [11]). People act differently; some may consider 'individual' membership as carte blanche to push their own proposals, others will still act exclusively on behalf of their employers, both regardless of the official membership rules.

From a theoretical perspective, one could argue that research into the role of the individual in the development of standards (probably not so much in the development of technology) is called for. Specifically, it would appear that one cannot necessarily assume that the professional background of a WG member, or the specifics of his/her employer have an immediate impact on the work done in the WG, or the views represented there. 
And in more practical terms: what can the interested companies do about this situation? After all, companies would like to see their corporate strategy and/or technology being promoted by the people they send to SSBs' working groups.

Companies would be well advised to educate the people they are sending to SSBs' working groups. This education primarily needs to cover relevant corporate strategies and goals that need to be observed. After all, it is a huge difference if a company's goal is to have a standard - any standard - in order to broaden or even create a market, or if they want to push their own technical solution. But education must not stop there - it should also cover more mundane aspects like SSBs' regulations and bylaws, as well as negotiation and diplomatic skills. Likewise, companies should manage their standards activities very carefully; this includes whom to send to which body. For instance, it may not always be advisable to send R\&D people who may tend to push their brainchildren rather than support the corporate strategy.

Unfortunately, whatever they do will hardly guarantee success - we are dealing with the human nature here .....

\section{References}

1. Buchanan, D.A.; Huczynski, A.A.: Organizational Behaviour. Prentice Hall (2004).

2. Williams, R.: The Social Shaping of Information and Communications Technologies. In: Kubicek, H. et al. (eds.), The Social Shaping of the Information Superhighways, Proceedings of International Conference, COST A4, European Commission DGXIII, Luxembourg (1997).

3. Williams, R.; Edge, D.: The Social Shaping of Technology. Research Policy Vol. 25, pp. 856-899 (1996).

4. Williams, R.: The Social Shaping of Technology: Research Concepts and Findings in Great Britain. In: Dierkes, M.; Hoffmann, U. (eds): New Technologies at the Outset Social Forces in the Shaping of Technological Innovations. Campus/Westview (1992).

5. Egyedi, T.; Jakobs, K.; Monteiro, E.: Helping SDOs to Reach Users. Report for EC DG ENT, Contract No 20010674. http://www-i4.informatik.rwth-aachen.de/ $\sim$ jakobs/grant/Final_Report.pdf (2003).

6. Jakobs, K.: (E-Business \& ICT) Standardisation and SME Users - Mutually Exclusive? Proc. Multi-Conference on Business Information Systems, Track 'E-Business Standardisierung und Integration, Cuviller Verlag, Göttingen, (2004).

7. Jakobs, K.; Procter, R.; Williams, R.: The Making of Standards. IEEE Communications Magazine, vol. 39, no. 4, (2001).

8. Spring, M.B.; Weiss, M.B.H.: Financing the Standards Development Process. In: Kahin, B.; Abbate, J. (eds): Standards Policy for Information Infrastructure. MIT Press, (1995).

9. Jakobs, K.: Shaping User-side Innovation Through Standardisation - The Example of ICT. Technological Forecasting and Social Change, Elsevier, vol 73, no 1, (2006).

10. Jakobs, K.; Lemstra, W.; Hayes, V.; Tuch, B.; Links, C.: Towards a Wireless LAN Standard. To be published in: Lemstra, W.; Groenewegen, J.; Hayes, V. (eds): The Innovation Journey of WiFi. Cambridge University Press (2010).

11. ISO: ISO/IEC Directives, Part 1 - Procedures for the technical work. http://www.iec.ch/tiss/iec/Directives-Part1-Ed6.pdf, (2008). 